\title{
Chapter 1 \\ Building Teacher Capacity to Educate the Whole Child. Lessons \\ from Comparative Experience
}

\author{
Fernando M. Reimers
}

\begin{abstract}
How should teachers be prepared in order to educate their students to address the most pressing issues of the future? Conducted over the years 2018-2019, this book presents the results of a study of large-scale teacher professional development programs that aimed at equipping students for the uncharted territory of a rapidly changing world. This introductory chapter traces the roots of the impetus to educate students holistically, helping them develop a broad range of cognitive and socio-emotional skills. The chapter explains the value of comparative analysis to advance a robust theory of the role of professional development in instructional improvement which can guide implementation of large scale programs, and introduces a staged model of development of education systems, contingent on the level of skill and preparation of teachers and summarizes the key contributions of the chapters in this book. The chapter reviews previous research on the role of largescale teacher professional development in preparing teachers to lead their students in deeper learning and in developing a broad range of cognitive and socio-emotional skills. Given that much of that research has been generated in highly resourced environments, a staged model of development of education systems contingent on level of teacher preparation justifies attention to the role of professional development in more diverse contexts. The chapter further examines some literature on the implementation of large-scale educational change, setting the stage for a comparative study of largescale programs of teacher professional development. The chapter examines data from a recent cross-national survey of teachers to discuss their expressed needs for professional development and perceptions of the characteristics of the most effective professional development programs. Finally, the chapter synthesizes the findings of this study and draws out their implications for teacher development in ambitious system level reforms that aim at preparing students with a broad range of skills to invent the future.
\end{abstract}

\footnotetext{
F. M. Reimers $(\varangle)$

Harvard Graduate School of Education, Cambridge, MA, USA

e-mail: Fernando_Reimers@ @arvard.edu
} 


\subsection{Goals of This Book}

As countries around the world embrace more ambitious goals for schools, in order to prepare students for the demands of a rapidly changing world and for the uncharted territory of the future, there is growing interest in the question of how best to support teachers so they can lead powerful and relevant instruction aligned with those aspirations. This book is an analysis of six large-scale efforts at building teacher capacity to lead instruction in an ambitious range of cognitive and socio-emotional domains essential for our times. These large-scale programs of teacher professional development were implemented in Cambodia, Colombia, England, India, Mexico and the United States.

The book builds on previous work of the Global Education Innovation Initiative, a research and practice consortium I lead that aims to understand how to transform public education systems so they can empower students with the competencies essential for civic and economic participation in the twenty-first century. We advance this goal through three inter-related activities that seek to create synergies between education policy, research and practice: conducting applied research, leading informed dialogues designed to develop collective leadership and developing tools which can support powerful instruction aligned with the development of the breadth of skills essential to build a better world. We have so far conducted four applied studies and a fifth theoretical study. The first study is a comparative analysis of curriculum in light of what is known about the cognitive, inter and intrapersonal competencies essential for civic and economic participation in our times (Reimers \& Chung, 2016). The second is a comparative analysis of teacher professional development programs that prepare teachers to help their students gain the breadth of skills essential in our times (Reimers \& Chung, 2018a). The third is a cross-national evaluation of the impact of secondary school curriculum designed to empower youth to become entrepreneurial (Reimers, Ortega, \& Dyer, 2018b). The fourth study is a comparative analysis of ambitious national curriculum reforms in eight different countries (Reimers, 2020a). The fifth study develops a theoretical model to account for the multidimensional nature of educational change, used to integrate a vast empirical literature in the field of global education, explicating how change is concurrently a cultural, psychological, professional, institutional and political process (Reimers, 2020b).

The informed dialogues we have organized seek to make visible the knowledge education leaders and practitioners have gained as they advance educational change, and to integrate this knowledge with knowledge based on research and with practical instruments to further educational change for the purpose of supporting collective leadership that can align schools and school systems with the urgent need of relevance. We have published three books based on these informed dialogues. The first book is an analysis of opportunities to transform teacher education in Massachusetts, informed by a study of the way in which Singapore aligned teacher preparation with an ambitious vision for education in the twenty-first century conducted by several educators from Massachusetts (Reimers \& O’Donnell, 2016). The second, an expert 
report on the challenges of scaling ambitious education reforms and innovations that aims to support the development of a broad range of competencies in schools (Reimers, 2017). The third book is a study of the lessons learned by system-level leaders as they advanced ambitious national education reforms (Reimers, 2019).

Finally, we have developed a series of practical tools and curriculum protocols to support ambitious educational change that helps students gain the necessary competencies for civic and economic participation in rapidly changing contexts. These include a guide to lead a process of consensus building to establish systems that support a high-quality teaching profession (Reimers et al., 2017a), and three projectbased, interdisciplinary, curriculum resources aligned with a broad range of cognitive and socio-emotional competencies necessary to achieve the United Nations Sustainable Development Goals and Universal Human Rights (Reimers, Chopra, Chung, Higdon, \& O’Donnell, 2016; Reimers et al., 2017b, 2018c).

I have carried out this work in collaboration with colleagues from various countries and with varied disciplinary backgrounds. This diversity of experience and backgrounds has enriched our thinking and enhanced the relevance of the products of our work to the realities of diverse education contexts. I have included my graduate students at Harvard in some of these collaborations, for example, in the design of curriculum resources aligned with the United Nations Development goals. Not only are the graduate students education professionals, who bring with them experience in diverse countries; I believe professional preparation must bridge the worlds of research with the worlds of practice, by actively engaging graduate students with the worlds of policy and practice as part of their studies.

Conducted over the years 2018-2019, this book presents the results of a study of large-scale teacher professional development programs. The 22 authors of the six-country studies analyzed in this book are educators with professional experience in 17 countries, including the six countries studied. Their experience covers a variety of education roles, including teachers, coaches and managers in professional development organizations, consultants to schools and school districts, government officials, and education specialists in foundations, international development organizations. These six-country studies started in the context of a graduate course I teach in comparative education policy analysis. This course reflects some of the intellectual interests and research questions which also inform the Global Education Innovation Initiative. I invited my graduate students to identify national education reforms or large-scale programs aimed at helping build the capacity of teachers to prepare the students with the breadth of skills necessary for civic and economic participation in the twenty-first century. Students in this course read the first two books resulting from the applied research of the Global Education Initiative: Teaching and Learning in the Twenty First Century, and Preparing Teachers to Educate Whole Students, and used them to frame their studies. They were specifically invited to take the conclusions of our recent study of teacher professional development as hypotheses, and to test them against the case studies they themselves would conduct. We discussed their studies as they progressed, and I provided feedback to their papers analyzing their findings, which they then presented at a conference where they received additional feedback from peers and leaders in the field of international education, such as the director of 
education of the World Bank, former vice-ministers of education and senior leaders of international development organizations. Further discussions and revisions to their chapters extended beyond the course, in efforts to have coherence across these chapters in this book which was completed once these students had all received their masters' degrees from Harvard.

\subsection{Content of the Book}

In the studies presented in the chapters that follow, we examined large-scale reforms which explicitly focused on building the capacity of teachers to teach to a broader set of goals, either higher levels of cognitive goals, or a breadth of cognitive and socioemotional skills. The chapters were written from an available evidence base of program documents, evaluations (if available), as well as interviews with senior leaders and participants in the programs studied. The goal of these studies was to document carefully how these large-scale efforts of teacher education had been designed, how they were been implemented and, where the necessary information was available, with what results.

The resulting book is a comparative study of how large-scale teacher professional development programs are designed and implemented. This book does not attempt to answer the question of which of these programs is more effective than others, or even to assess whether these programs achieve their goals, but rather to illuminate how these large-scale efforts were designed, delivered in practice and with what results to date. We also examine whether these case studies confirm or disconfirm the conclusions reached in our previous study of large-scale programs of teacher professional development, and other conclusions of studies of professional development reviewed in this chapter. We hope this book will be of use to education leaders interested in designing and implementing programs of teacher professional development that are aligned with ambitious instructional goals.

In my experience working with ministers of education and other senior education leaders I have learned that it is often valuable to them to know how others have addressed problems similar to their own. This is especially crucial in the case of teacher professional development policies because, while there is a growing body of evidence supporting the importance of having skilled teachers, evidence about how to increase teachers skills, particularly at a large scale, is scarcer. This places many policymakers in the conundrum of realizing they must increase teacher quality but not necessarily knowing how to achieve this. The consequences of having to design strategies to implement large scale teacher professional development programs in the absence of knowledge can be disastrous, as will be discussed later.

For example, in 2011 the Grattan Institute, a public policy think-tank in Australia, conducted a study about the factors which contributed to the educational performance of countries in East Asia where students achieved at high levels in cross-national studies and where there was high equity in how students from different social background performed in such tests. The study identified that a key factor undergirding the high 
levels of performance of those teachers was high-quality teacher initial preparation and professional support that includes mentoring, opportunities for teachers to conduct research, classroom observations and peer-feedback, and access to master teachers (Jensen, Hunter, Sonnemann, \& Burns, 2012, 13). While this report describes what these high-performing systems do, it does not explain how they got to be able to do it and how the process of putting in place the supports to do these practices developed. The same limitation in understanding the process of change is evident with other studies that rely on cross-national evidence which identify high-quality teacher professional development as a correlate of high levels of students learning (Schleicher, 2018) or on synthesis of studies that identify which factors contribute to higher levels of student learning (World Bank, 2018). Knowing that countries like Singapore or cities like Shanghai provide teachers high-quality initial and ongoing professional preparation does not explain how they developed the capacity to do it or what processes they followed to get to the point at which they are at present. But it is precisely the development of such institutional and teacher capacity, via policies and programs, and especially via the design of effective implementation strategies, which is of greatest interest to the education reformer that is trying to improve a system where such supports for teachers are not yet available. A reformer in a country in need of high-quality professional development cannot just wish to be Singapore or Shanghai, they need to develop a detailed plan to carry out activities that will offer such development and the details of such plan, whether coaching will be involved, who will provide the coaching, whether professional communities and networks will be established, how, with what support; hence clarity about those details is fundamental. It is one thing to know that coaches should be selected on the basis of certain attributes such as deep knowledge and pedagogical knowledge, it is quite another to know what steps to follow to ensure mechanisms of selection that actually deliver what is intended. We hope that the analysis of the process followed by six countries as they built this capacity will contribute to filling that crucial knowledge gap regarding the process of supporting the development of teacher capacity on a large scale.

The instructional goals that guide the six programs included in this book are similar in that they all represent efforts to broaden and deepen curricular aspirations, but they differ in that each program takes this expansion of curricular goals in different directions. In the work of the Global Education Innovation Initiative we have learned that various groups use different terminologies, and different meanings, to reflect such broader education goals. In fairness, ambitious education goals for education are not exactly new. In advocating the cultivation of autonomy and the capacity for independent thinking Jean Jacques Rousseau was proposing goals for education that were as ambitious as the idea that ordinary people could govern themselves, which he and other philosophers of the enlightenment proposed in the eighteenth century (Soëtard, 1994b). Inspired by Rousseau, Johann Henrich Pestalozzi also proposed that the goal of education was to educate the full range of human capacities (Soëtard, 1994a). Similar ambitions were advanced by educators such as John Dewey or Maria Montessori in the early twentieth century (Röhrs, 1994; Westbrook, 1993). When the goal of educating all children was included in the Universal Declaration of Human Rights, in 1948, the implicit rationale was that education would help develop 
a broad range of competencies, as education was expected to help advance all other human rights, a tall order indeed involving a broad range of knowledge, skills and dispositions. UNESCO, the organization established to help achieve universal education, has thrice in its history, established high-level commissions with the mandate of helping inform global conversations about how to align education to growing skill demands in a rapidly changing world. The first of those commissions produced the report "Learning to Be" which emphasized the importance of cultivating not just basic literacies, but the capacity for lifelong learning (Faure et al., 1972). The second of those commissions produced the report "Learning: the treasure within" which highlighted that in order to prepare individuals to address the challenges of the present, a broad range of competencies would be essential: learning to know, learning to do, learning to be and learning to live together (Delors et al., 1996). The third of those commissions on the Futures of Education was established at the meetings of the United Nations General Assembly in September of 2019 and is expected to produce a report by 2021 .

Around the same time the Delors Report was being prepared, arguably motivated by technological and social developments and globalization, other international organizations and governments engaged in rethinking what skills and competencies would be necessary to participate in the twenty-first century, among them, the Definition and Selection of Key Competencies OECD Project. These efforts inspired changes in the curriculum in many countries, broadening their goals. A conclusion of our study of such efforts of curriculum revision in six countries was that it placed the topic of teacher professional development squarely at the center of reform efforts (Reimers \& Chung, 2016).

When we started the work on the Global Education Innovation Initiative 6 years ago, we adopted the term "Twenty-first century skills" to describe the broad range of competencies necessary to participate in the twenty-first century. Our first study of curriculum goals built on a report of the National Research Council in the United States synthesizing skills for life and work in the twenty-first century as encompassing: cognitive, inter- and intrapersonal skills (Pellegrino \& Hilton, 2012). Because we realized not all nations used the term twenty-first century skills to describe their efforts to broaden the curriculum, in our first study of teacher preparation programs we used the term "educating whole children". Other authors use the term "deeper learning", or cognitive and socio-emotional development, and others use breadth of skills (Jones \& Doolittle, 2017; Mehta \& Fine, 2019). One of the questions the studies presented in the chapters in this book answer is how does each of these reforms define these broader goals. Specifically, we examine their stated goals against the framework developed by Pellegrino and Hilton to summarize twenty-first century skills, summarized below.

\section{Cognitive Skills}

1.1 Processing and cognitive strategies

- Critical thinking

- Problem-solving

- Analysis 
- Logical reasoning

- Interpretation

- Decision making

- Executive functioning

1.2 Knowledge

- Literacy and communication skills

- Active listening skills

- Knowledge of the disciplines

- Ability to use evidence and assess biases in information

- Digital literacy

1.3 Creativity

- Creativity

- Innovation

\section{Interpersonal skills}

2.1 Collaborative group skills

- Communication

- Collaboration

- Team work

- Cooperation

- Coordination

- Empathy, perspective taking

- Trust

- Service orientation

- Conflict resolution

- Negotiation

2.2 Leadership

- Leadership

- Responsibility

- Assertive communication

- Self-presentation

- Social influence

\section{Intrapersonal skills}

3.1 Intellectual openness

- Flexibility

- Adaptability

- Artistic and cultural appreciation

- Personal and social responsibility

- Intercultural competency

- Appreciation for diversity

- Adaptability

- Capacity for lifelong learning

- Intellectual interest and curiosity

3.2 Work Ethic. Responsibility 
- Initiative

- Self-direction

- Responsibility

- Perseverance

- Productivity

- Persistence

- Self-regulation

- Meta-cognitive skills, anticipate future, reflexive skills

- Professionalism

- Ethics

- Integrity

- Citizenship

- Work orientation

\subsection{Self-efficacy}

- Self-regulation (self-monitoring and self-assessment)

- Physical and mental health

Whereas our previous study of teacher professional development focused on programs most of which were led by organizations of civil society, the six programs examined in this book are government programs advanced by national or state governments. Some have been developed with the aim of supporting a significant number of teachers in the national education system, while others are more targeted programs focused on networks of schools, or schools serving particular groups of students. We find interesting complementarities between the strategies followed by these two kinds of programs, and think that the design of future large-scale government programs might benefit from combining the implementation of these strategies and practices. The national programs include a program to improve mathematics instruction in England, a national program to improve the quality of instruction in rural schools in Colombia and a national program of teacher professional development to support the implementation of an ambitious education reform in Mexico. The programs of professional development in networks of schools include one in a network of schools serving marginalized students in the state of Telangana in India, one in a network of innovative schools in Cambodia and one in Burlington, a small school district in the United States. The specific focus of these programs is summarized below.

The chapter "Supporting mathematics instruction for mastery in England" examines an ambitious national reform aimed at providing all teachers with the pedagogical competencies to improve levels of mathematical knowledge and understanding and closing equity gaps in mathematics, beginning in 2014. Embedded within a set of broader education reforms initiated in 2010 to raise education standards, the focus of this reform is on the development of higher order math skills. The reform sought to promote more collaboration among teachers within and between schools in a context of increasing school autonomy and accountability. The reform was introduced alongside a new knowledge-based national curriculum and reformed assessments. The new primary mathematics curriculum was informed by curricula in East Asian countries, which sought to develop fluency, reasoning and problem-solving. The 
teaching for mastery reform was a pedagogical reform that sought to complement the new national curriculum. It included study trips for headteachers and teachers to see schools and math teaching in Shanghai. The three core elements of the reform include a lead specialist teacher exchange program between England and Shanghai, a professional development program led by Maths Hubs and specially designed textbooks. The Maths Hubs bring math teachers in a network of 37 hubs, each lead by an outstanding school or college to develop and disseminate outstanding practice. Lead specialists in schools are trained as Mastery specialists and are then responsible for leading whole school training on the mastery approach in their school, as well as working with local teachers from other schools. The focus of the professional development activities includes strengthening teachers' subject knowledge, pedagogical knowledge of mastery teaching, practice to support student differentiation, lesson planning and assessment.

The chapter "Supporting all teachers in learning in Colombia" examines a national program of professional development (Todos a Aprender) launched in 2012 as a largescale effort to close the urban-rural achievement gap. This program resulted from a partnership between a private education advocacy organization and the Ministry of Education. Initially, the program involved multiple interventions to support rural schools, such as in-service training, support of school management, infrastructure, nutrition and stakeholder support. Over time, the program evolved to focus exclusively on teacher professional development and classroom materials. With a teachercentered design, and following a cascade training model, the program reaches over 100,000 teachers with 4,200 lead teachers led by 100 trainers. Teachers participating in the program engaged in four workshops a year and in follow-up coaching in their school by lead teachers. The program also created professional learning communities that provided ongoing opportunities for teachers to collaborate, reflect on their practice and develop instructional materials. Textbooks with lesson plans and suggested instructional activities became an integral component of the program, facilitating teacher collaboration and communication.

The chapter "Policies for Teacher Professionalization in Mexico's Education Reform" examines the role of professional development programs in the context of an ambitious education reform which revamped the curriculum to align it with twentyfirst century skills. The reform created a new education model, which encompassed five core elements: (1) schools at the center, (2) standards and curriculum, (3) teacher professional development, (4) inclusion and equity, and (5) governance. The reform included increased accountability for teachers, principals and students, and catalyzed greater governmental control in education. The reform created a professional teaching service law designed to professionalize teacher selection and advancement. The National Institute of Educational Evaluation, which received constitutional autonomy under the reform, was tasked with devising an evaluation framework to evaluate principals, teachers and students. Professional development contemplated the creation of networks within and among schools to promote the exchange of best practices. Online training and lectures reached the most teachers. The teacher networks for peer-to-peer exchange of experience allowed teachers to reflect on their practice. However, the supervisory component of this initiative was not well-received 
by teachers and did not reflect the goals of the curriculum and did not yield specific instructional plans reflecting the goals of the curriculum.

The chapter "Building teacher capacity at the Telangana Social Welfare Residential Educational Institution Society" examines a school network established in 1984 to provide free, residential, high-quality education to low-income students from scheduled castes and tribes in the state of Telangana, in India. The program received significant political support in 2014, growing as a result to cover 268 schools and colleges and serving 130,000 students. The schools aim to provide a high-quality, holistic, value-based education to students, cultivating skills for work and life. A coherent curriculum framework guides their efforts, supported by a range of programs to build the professional capacities of teachers and administrators, including pre-service and in-service teacher education programs, as well as professional development programs for school leaders. The core form of teacher professional development consists of periodic meetings throughout the year that bring school leaders and teachers together to discuss the ongoing instructional challenges. In addition, support from external providers of professional development assists teachers in developing knowledge and pedagogical knowledge.

The chapter "Cambodia's New Generation Schools Reform” examines a targeted reform launched by the Ministry of Education in 2015, which provides a unique combination of autonomy, accountability and funding to ten "New Generation Schools" tasked with innovating in curriculum and instruction to prepare students for the twenty-first century workforce. Expected to reach 100 schools by 2022, the reform is one of the 15 initiatives of the Cambodian National Education Strategic Plan. This program is anchored in a theory that the creation of a system and culture of high teacher professionalism and high-quality professional development will support innovative teaching and learning. The program includes an innovative and selective initial teacher education program focusing on academic leadership, professional ethics, mentoring and twenty-first century skills. Additionally, New Generation School teachers receive ongoing professional development through the Formative Teacher Support System, which is centered on the practice of reflective teaching, where teachers reflect on their practice individually and in collaboration with colleagues and experienced mentors. The Formative Support System encompasses a range of modalities of teacher professional development: visits to other schools and other countries, professional learning communities, career path planning, individual feedback, classroom observations and ongoing in-service training.

The chapter "Twenty first century learning in Burlington Public Schools" examines how a high-performing school district in the State of Massachusetts, in the United States, promotes curricular and instructional innovation fostering a culture of collaboration, trust and professionalism. Burlington's strategy is anchored in building a collaborative and participatory culture in the six schools in the district, promoting instructional coherence and alignment around a balanced set of education goals that include cognitive skills as well as socio-emotional competencies, and in building trusting relationships among all key stakeholders in the school. Relying on a participatory process to define district goals, Burlington engages all key stakeholders (students, parents, teachers, staff, administrators and school board members) to develop 
3-year improvement plans with agreed upon goals and with strategies to build the capacity necessary to achieve those goals. The district uses periodic assessment of the intended outcomes as a way to manage the improvement process. Scheduled staff meetings and specific training develop the capacities of teachers to support socioemotional learning and the cognitive goals of the district. Professional development opportunities include a wide range of approaches, from formal staff meetings, observing classroom instruction, reviewing assessment data and discussing improvement strategies, receiving feedback from coaches in specific subjects, as well as working collaboratively with colleagues. As a result of these efforts, schools in the district offer a range of curricular and extra-curricular opportunities for students to master academic competencies, develop socio-emotional skills and engage in service-learning projects. Central to these efforts is the role of district leadership in supporting a coherent and collaborative culture of ongoing improvement.

\subsection{The Value of Comparative Analysis to Understand How Professional Development Improves Instruction}

The importance of teacher quality has long been understood. As an intentional process designed to support learning, it stands to reason that the effectiveness of this process is the result of the knowledge and skill of those guiding it. One of the persons who exerted most influence in placing the topic of teacher education on the agenda of governments and international development institutions in the 1960s was Clarence Beeby. As New Zealand's director of education and chief education advisor to the government between 1940 and 1960, Beeby led one of the most ambitious education reforms to equalize educational opportunity, well before this goal would be embraced by other nations in the 1960s (Beeby, 1992). In that role, Beeby discovered the importance of teacher professional development to transform policy intentions into changed classroom practices. He distilled those lessons in the book "The Quality of Education in Developing Countries", which he wrote at Harvard University, where he spent several years in the early 1960s (Beeby, 1966). Beeby's ideas exerted great influence in the international development community through his leading role in the executive board of UNESCO and in the early years of UNESCO's International Institute for Educational Planning.

Beeby theorized that the quality of education in a nation developed through a series of four stages, and that each stage was defined by the level of professionalism of teachers. The first stage, which he called "the Dame school", had teachers which were largely untrained and poorly educated. The second stage, which he termed "Formalism", was characterized by trained teachers, but still ill-educated. The third stage, which he called "Transition", featured teachers who were trained and better educated. The fourth stage, called "Meaning", featured teachers who were well educated and well trained. These stages shaped distinct characteristics of the education systems. In the Dame school stage, education was unorganized, the focus was on very narrow 
subject content, with very low standards, and memorization was the main goal. In contrast, in the stage of Meaning, the focus was on meaning and understanding of what was learned, a wider curriculum, offering more variety of content and methods, individual differences were recognized, pedagogy relied more on active learning emphasizing problem-solving and creativity, and the goals were to develop cognitive skills as well as emotional and aesthetic dispositions (Beeby, 1966, p. 72).

At a time when the primary pre-occupation of governments and international development institutions was with the quantitative expansion of education in order to achieve education for all, Beeby's ideas offered a model that gave paramount importance to quality and provided a strong rationale for teacher professional development, as an avenue to help countries move their education systems to stages where students could find more meaning in their education.

Beeby's idea that the quality of teaching was one of the most important influences on student opportunity to learn has been confirmed by subsequent research, as demonstrated in a synthesis of over 800 meta-analysis of factors influencing student achievement (Hattie, 2009). An analysis of cross-national teacher reports on professional development in 35 countries similarly demonstrates that access to high-quality professional development increases the range of instructional strategies teachers use (Barrera-Pedemonte, 2016, p. 9).

While there is a robust body of knowledge on the importance of teacher quality and about the principles and practices which are effective in helping teachers gain knowledge and skills, much of that knowledge has been generated in highly institutionalized and well-resourced contexts. It is therefore reasonable to ask whether the effectiveness of those principles and practices "transfers" to other settings. While Beeby's model assumed that the education systems in all countries should progress through the same stages, his model suggests that for countries at different stages different interventions may be appropriate to improve quality. For instance, while many authors argue that school autonomy is desirable to recognize and foster teacher professionalism, it is not self-evident that in schools where teachers are ill-educated and ill-trained, autonomy will lead to greater opportunities to learn for students, or even to greater professionalism.

We might conclude then that the focus, and perhaps even approaches, on teacher professional development should be aligned to the "stage" of an education system, to the characteristics of the majority of their teachers. For instance, in a system in which teachers have very limited knowledge of the subject matter they teach, or of the pedagogies effective in teaching it, professional development based on learning communities in schools is unlikely to yield the same results as in contexts where teachers are highly trained. The value of comparative analysis is to inform what educational approaches, to preparing teachers in this case, are most appropriate in any given context. For instance, a recent cross-national study of teachers and principals, covering mostly early industrialized countries, concludes that given that most teachers already attend training focused on knowledge, this is not an area of great need in OECD countries, instead training opportunities in information and telecommunication technology, teaching methods for multicultural settings and teaching for students with special needs are a much greater priority (OECD, 2019, p. 152). Clearly, this 
conclusion regarding the low priority of knowledge-based professional development should not be extrapolated to countries where similar opportunities are not available to most teachers. While most researchers know that research findings should not be extrapolated outside the observed range of variation of the factors which they have studied, this fact is sometimes forgotten when those looking for 'good practices' draw insights from 'high performing systems' and try to generalize their validity to contexts which are quite different from the contexts of such high performers. One should think carefully about the generalizability of cross-national studies such as the OECD PISA studies, or the studies of the International Association for the Evaluation of Educational Achievement, or of research conducted on school settings in nations such as Australia, Canada, the United Kingdom or the United States, to countries where education systems are at different stages of development, in terms of Beeby's characterization of the term. It is not that those findings should be dismissed entirely, but rather that they should be treated as hypotheses, in need of further empirical confirmation. It is also helpful to keep in mind, when looking for comparative experience, that some countries have shown greater improvement over the last two decades in cross-national assessments such as PISA than others.

A review of the research on teacher professional development in developing countries identifies a shift from the traditional view of "staff development" or "in-service training" consisting of workshops or short-term courses, toward a recognition of the importance of a broad range of activities that support professional development, understood as "a long term process that includes regular opportunities and experiences planned systematically to promote growth and development in the profession" (Villegas-Reimers, 2003). This new perspective of professional development recognizes that "professional development may look and be very different in diverse settings, and even within a single setting, it can have a variety of dimensions" (Ibid., 15). This review identifies a variety of teacher professional development models which fall into two broad categories: organizational partnership models and small group or individual models. Organizational partnership models include: professional development schools, other university-school partnerships, other institutional collaborations, school networks, teacher networks and distance education. Small group or individual models include: supervision, student performance assessment, workshops and seminars, case-based study, self-directed development, cooperative development, observation of excellent practice, teachers participation in new roles, skill-development models, reflective models, project-based models, portfolios, action research, teacher narratives, cascade models and coaching (Ibid., 70).

Another review of a decade of research on teacher professional development published in the journal Teaching and Teacher education highlights the contextual nature of determining what kind of professional development is most appropriate:

The instruments used to trigger development also depend on the objectives and needs of teachers as well as of their students. Thus, formal structures such as courses and workshops may serve some purposes, while involvement in the production of curricula, the discussion of assessment data or the sharing of strategies may serve other purposes. Not every form of professional development, even those with the greatest evidence of positive impact, is of itself relevant to all teachers (Avalos, 2011, 10). 
There is a growing recognition that we need more nuanced conceptualizations to understand what constitutes quality in professional development. Desimone has proposed the following features as key: content focus on subject matter, collective participation of teachers from the same school, active learning for teachers, duration with longer programs being more effective and coherence with the goals of the education policies that support them (Desimone, 2009).

Education specialists at the World Bank have developed a conceptual framework to facilitate cross-national education comparisons and benchmarking: the Systems Approach for Better Education Results (SABER). The framework documents policies and practices in place in countries with respect to early childhood development, workforce development and tertiary education; with respect to four quality and system support domains: student assessment, teachers, information and communication technologies and school health and school feeding; and in four governance and finance areas: school finance, school autonomy and accountability, education and management information systems and engaging the private sector. For each of those cycles, domains and areas, countries practices are scored on a rubric that characterizes it as latent (indicating there is no policy), emerging (reflecting some good practice), established (signaling good practices in place) and advanced (reflecting international best practice).

The SABER framework can be used to provide a systemic characterization of a country's education policies and institutions. For example, a World Bank study of education in Shanghai finds very high coherence between policy and implementation using the framework (Liang, Kidwai, \& Zhang, 2016). Central to such high fidelity in the implementation of coherent education policies is attracting and developing an excellent teaching force, aligned with "Clear learning objectives and standards, compact and well-aligned teaching learning materials, and efficient evaluation systems for all subjects across all grade levels" (Ibid., xviii). The education law creates accountability mechanisms and clear expectations for teachers to foster the holistic development of students, as well as their own professional development. Among all the eight domains of teacher policies identified in the SABER framework, Shanghai's policies score was either established or advanced. Those domains are: setting clear expectations for teachers, attracting the best into teaching, preparing teachers with useful training and experience, matching teachers' skills with students' needs, leading teachers with strong principals, monitoring teaching and learning, supporting teachers to improve instruction and motivating teachers to perform (Ibid., 21).

"Shanghai designs professional development activities to be collaborative and to focus on instructional improvement. School principals are responsible for creating targeted teacher training plans based on each teacher's evaluation results. Professional development is often a substantial part of schools' operational expenditure. The city pairs weak and inexperienced teachers with high performing and experienced ones. Important platforms for teacher professional development and performance evaluation - teaching-research groups and lesson observations-are also practiced universally in schools. Teachers are expected to be researchers who evaluate and modify their own pedagogy in relation to student outcomes. The city requires new teachers to complete at least 360 hours of professional development in their first five years of service, and an additional 540 hours to be considered for a senior 
rank... Overall, Shanghai is characterized by a coherent and comprehensive system of teacher professional development that incorporates multiple layers of in-service training, school-based teacher research groups, evaluation of teacher performance, and a structured career ladder that provides both motivation and a mechanism for teachers to progress in their careers, which is key to Shanghai's demonstrated excellence in education" (Idem, xix).

A study of the characteristics of effective teacher professional development programs in Australia, which examined the reports of 3,250 teachers who had participated in 80 professional development programs, found that a number of characteristics of those programs were critical to their effects (Ingvarson, Meiers, \& Beavis, 2005). The program's focus on content and follow-up in the classroom was the main contributor to teacher's knowledge. Opportunities for active learning and reflection on practice were the main contributors to practice. In terms of impact on student learning and efficacy, feedback is an important predictor, as well as content focus and active learning (Ibid., 14-15).

A recent study of teachers conducted by the OECD in 44 countries shows that teachers describe the most impactful professional development programs are "based on strong subject and curriculum content and involve collaborative approaches to instruction, as well as the incorporation of active learning" (OECD, 2019, 44).

The existing knowledge about characteristics of effective professional development programs underscores the importance of embedding these programs in the context in which teachers work. It is in the context of doing their work that most teachers must find opportunities to examine their practice and learn about new approaches to improving instruction. An evolving perspective of schools as learning organizations highlights the many ways in which professional development requires the creation of a school culture that supports it. A recent summary of that literature highlights that schools as learning organizations: develop a shared vision centered on the learning of all students, create and support continuous learning opportunities for all staff, promote team learning and collaboration among staff, establish a culture of inquiry, innovation and exploration, establish systems to collect and exchange knowledge and learning in school, learn with and from the external environment, and model and grow learning leadership (Kools \& Stoll, 2017). A corollary of this literature is that sustainable programs of teacher professional development should seek to create such culture in schools.

Fullan had earlier identified the importance of organizational culture of the school to successful teacher development (Fullan, 1987). Changing school culture is a tall order indeed, one that requires sophisticated policy initiatives that can recognize the importance of local context and allow for "mutual adaptation" between policy intents and school realities. The need for policies to allow for "mutual adaptation" from particular schools is a corollary of Beeby's model of how education systems, understood here as schools, reflect the kind of teachers they engage, or of the more recent model to conceptualize how professional development influences teacher change developed by Guskey positing that change is a gradual and difficult process for teachers. In order to change, teachers must receive regular feedback on student learning progress, and to achieve sustained change teachers must receive continued follow-up, support and pressure (Guskey, 2002). 


\subsection{The Importance of Studying the Implementation of Large-Scale Programs of Teacher Professional Development}

Given the robust evidence supporting the importance of teacher quality, and suggesting approaches to improve it, it is paradoxical that many of the ongoing government efforts of teacher professional development do not have more impact. A review of teacher professional development studies in the United States concludes: "Despite recognition of its importance, the professional development currently available to teachers is woefully inadequate. Each year, schools, districts, and the federal government spend millions, if not billions, of dollars on in-service seminars and other forms of professional development that are fragmented, intellectually superficial, and do not take into account what we know about how teachers learn" (Borko, 2004, 3).

A possible reason is that many government policies in practice still reflect a traditional view of development as in-service training model, whereas the evidence supports a more complex view of development. Reviews of research on teacher professional development conclude that research in the field has moved away from the traditional in-service training to understanding professional development as a complex process which can be supported by a range of approaches (Avalos, 2011; Villegas-Reimers, 2003). A recent review of teacher professional development programs in the United States acknowledges that many professional development initiatives are ineffective in changing teacher practice and student learning (DarlingHammond, Hyler, \& Gardner, 2017). This study reviewed 35 studies demonstrating a positive impact of professional development, teacher practices and student outcomes, and identified that these programs shared these characteristics: focused on curriculum content, incorporated active learning, supported teacher collaboration, used models of effective practice, provided coaching and expert support, offered feedback and reflection, and provided extended time to learn, practice, implement and reflect (Ibid).

However, much of what we know about the contributions of teacher professional development to teacher knowledge and practice comes from small-scale studies designed to create an existence proof "to provide evidence that a professional development program can have a positive impact on teacher learning" (Borko, 2004, 5). Given this limitation in our knowledge base, the task of designing large-scale programs of professional development inevitably involves design, a process of invention where the interventions designed can be informed by the evidence based, but must necessarily go beyond the knowledge-based making assumptions about how best to scale the principles documented in research. For instance, while many studies documenting the impact of professional development programs are based on well-selected and trained facilitators, and often on self-selected participants in the programs, designers of government programs must make assumptions about what is likely to work with facilitators who may not be as highly selected or trained, and for teachers who may be required to participate in professional development, rather than elect to participate in them. The imperatives of creating programs at scale 
thus translate the ideas about what works which are supported by evidence into program theories and theories about the implementation of those programs which are hypotheses, rather than empirically demonstrated facts.

It is arguably this process of "translation" that explains why so much professional development is of low quality. Simply put, it is easier for governments to implement professional development of low quality. Given that research shows that it is the quality of professional development that is critical, an important question is how best to design quality programs of professional development which can be implemented at scale. Examining the design of large-scale programs of professional development, in their program theory as well as theory of implementation, and in their results, is critical to informing the design of future programs.

On absence of such intentional design, it is likely that the implementation of teacher professional development policies will continue to transform them in ways that render them ineffective. For example, there is good evidence across 35 countries that engaging teachers in collaborative professional development is associated with teachers using pedagogies that foster deeper learning. In contrast, simply offering professional development engaging large numbers of teachers in school, without collaboration, is negatively related to the use of deeper learning pedagogies (BarreraPedemonte, 2016). A national program which tried to scale such processes with existing staff, teachers or school supervisors, without the skills to facilitate effective collaboration, is more likely to conflate training a large number of teachers in the school with true collaboration, and therefore unlikely to have impact, or to have negative impact, in fostering deeper learning.

Another example of the challenges of scaling effective approaches to professional development will reinforce this point of how easily the scaling process can transform programs in unintended ways which diminish their impact. A recent meta-analysis of 60 studies on the effect of teacher coaching found that teacher coaching had a positive impact on teacher practice and on student learning (Kraft, Blazar, \& Hogan, 2018). But developing the skills for effective coaching for large numbers of coaches is a demanding task. Governments trying to implement large-scale programs based on school embedded coaching without providing opportunities to build coaching capacities in schools are unlikely to achieve the same results documented in the studies just mentioned.

Existing evidence supports the idea that governments follow approaches which are easier to implement teacher professional development, even if they are ineffective. The latest OECD cross-national survey of teachers shows that while most teachers in the 44 countries participating in the study partake in some form of in-service training, the most popular approaches are attending courses and seminars outside of schools, whereas only $44 \%$ of the teachers participate in peer-learning and networking, even though collaborative learning is identified by the teachers in this study as the most impactful (OECD, 2019, 14).

Under pressure to achieve results in the short run, at low cost and depending on existing human resources, it is all too easy for administrators of programs to underestimate the level of skill necessary to support teacher development, such as the skill necessary to support true collaborative learning or to conduct effective coaching, 
or the investments necessary to build such level of skill. Many national programs still depend on cascade models of training, which too often result in a progressive loss of fidelity and quality of training with each successive level of replication.

Arguably, this difficulty in devising effective approaches to teacher professional development which can be implemented at scale is at the root of the paradox that in spite of the fact that teachers receive much professional development, and that they value it, too few teachers use pedagogies which foster deeper learning and too many students still learn significantly less than is expected, as documented in national or cross-national evaluations of student knowledge and skills. A recent cross-national study of teachers conducted by the OECD, for example, documents that only about half of the teachers in the 44 countries participating in the study use pedagogies that promote cognitive activation, such as getting students to evaluate information or apply knowledge to solve a problem, less than $60 \%$ give their students tasks that require critical thinking, $50 \%$ have students work in small groups to collaborate in solving a problem, $45 \%$ ask students to decide how to solve a complex task, $35 \%$ present tasks for which there are no obvious solutions and less than $30 \%$ have students work on projects that require at least a week to complete (OECD, 2019, 56). About a third of the teachers reports low self-efficacy in activating student motivation to learn or in supporting their students learning through technology (OECD, 2019, 66). Only $40 \%$ of the teachers allow students to evaluate their own learning (OECD, 2019, 60).

Even though this study shows that the majority of teachers and principals participate in professional development programs and most teachers report that such training positively impacted their teaching (OECD, 2019, 152), there is, however, great variation in the kind of professional development available to teachers, as most of them have access to courses and seminars outside their schools, but fewer participate in peer learning or networking. There are good practical reasons why governments rely on training designed in a top-down fashion, often depending on "cascade" or train the trainer models of professional development. This is easier to do than organizing school improvement networks in which teachers participate in multiple forms of professional development over an extended period, or in which they learn collaboratively. Evidently, what is easier to do or more practical to undertake may not be what is most effective. This is the reason evidence on what can be implemented at scale is necessary to design large-scale efforts of teacher professional development.

Another cross-national study of teacher professional development in 35 education systems, using data from the OECD Talis survey in 2013, demonstrates that curriculum-based professional development is more likely to influence instruction than subject-based or pedagogy-based curriculum, yet most professional development is subject matter and pedagogy-based, and there is great variation across countries in the percentage of teachers who participated in curriculum-based professional development. As a result, the focus for professional development most related to instructional change is the type of professional development least frequently available to teachers (Barrera-Pedemonte, 2016). The same study examined whether the professional development teachers had participated in featured four characteristics which have shown to contribute to teacher development: collective participation of 
several teachers from the same school, active learning, collaboration and duration. Most teachers participated in programs which did not have those characteristics, and less than half of the teachers indicate that their professional development includes these four attributes. Only professional development that involved collaboration was consistently associated with the use of teacher instructional practices that are beneficial to support deeper learning, such as engaging students in projects that take at least a week to complete, organizing them in small groups for cooperative learning and encouraging them to use information and communication technologies (Ibid., 10). The same study shows that in at least half of the countries, teachers with less pre-service training received professional development of lower quality (Ibid., 12).

Our recent study of teacher professional development programs aligned with educating the whole child shows that across diverse education systems, these programs shared a number of characteristics such as:

- They reflect a conception of adult learning that sees it as socially situated and responding to current needs of teachers for learning.

- They involve sustained and extensive opportunities for teachers to build capacities, often extending an entire school year, or spanning across multiple school years.

- The modalities of professional development are varied. They include independent study of new material, discussion with peers and others, individual or group coaching, demonstrations of new practices, independent research projects and opportunities for reflection.

- The curriculum of the programs examined covers a blend of capacities, from a broad focus on helping students develop particular capacities to a highly granular identification of particular pedagogies and instructional practices that can help students gain those skills.

- The curriculum of these various programs reflects a view of learning which includes cognitive skills, in interaction with dispositions and socio-emotional skills.

- Professional development includes exposure to visible routines, protocols and instructional practices, where teachers see in practice new forms of instruction or assessment.

- These programs rely on a mix of opportunities for learning situated in the context of the schools where teachers work.

- To support the intensive and sustained activities of professional development that these various programs advance, the organizations in charge build a range of partnerships with institutions outside of schools that contribute various types of resources.

- These programs see teacher practice as situated in specific organizations and social contexts, and in general adopt a whole-school approach, rather than helping individual teachers increase their capacity.

- These programs all develop capacities among teachers to advance pedagogies with the goal of developing competencies that are not formally assessed in the school or school system. The organizations that support these various programs all model a learning orientation. 
There is consensus that teacher professional development is part of a system in which other processes influence the quality of teachers. This has been called the continuum of professional development (Villegas-Reimers \& Reimers, 1996). With a group of colleagues including ministers of education, deans of teacher education institutions, exemplary highly effective teachers and other educators, we developed a protocol to support the creation of a shared vision which would enable the creation of a coherent continuum to support teacher quality. In this document, which we titled "Connecting the dots to build the future teaching and learning" we argued that there is only so much initial teacher education can do if the criteria to attract and select teachers into the profession are not aligned with professional standards. Similarly, we thought there were limits to the extent to which in-service professional development could remedy deficient initial teacher preparation (Reimers et al., 2017b). We proposed seven actions to achieve such systemic coherence and alignment:

1. Build a narrative about improving teaching quality as a national priority

2. Map and audit the system of programs and policies that sustains teaching quality

3. Develop a strategic teaching quality framework and professional standards that create coherence in the system which supports teacher quality

4. Empower teachers as professionals. Develop career pathways

5. Ensure a robust pipeline of qualified entrants into teaching

6. Support highly effective initial teacher preparation

7. Support developmental professional trajectories for teachers that produce highly effective teaching.

This protocol emphasized the importance of translating each of these seven steps into a clear sequence of activities, a real implementation plan, which could help execute bold ambitions into changed practices.

One of the elements in that continuum, the design of programs of teacher professional development which can be implemented at a large scale, would benefit from knowledge based on what has been attempted in practice. Five decades ago, the study of the results of government policies showed that implementation often does not follow the intended design and that the way in which policies were transformed at the implementation process could transform outcomes in important ways. This realization led scholars of evaluation to propose that any program evaluation should include a direct study of what exactly was the program which had been evaluated (Weiss, 1998). An entire field of practice in public policy has been developed focusing on the implementation of public policy, including techniques such as project planning, project management and approaches such as "Deliverology", the science of delivery (Barber, Moffit, \& Kihn, 2011).

Because much of the evidence about "what works" in teacher professional development has been derived from small settings, and from a limited set of national and institutional contexts, structuring the delivery of professional development programs at a large scale requires more than knowledge about evidence on which principles have proven to influence teacher knowledge and skills. Implementing largescale programs must be informed by knowledge of how other large programs have 
been designed and implemented. We hope this book contributes that kind of knowledge with the necessary nuance and granularity to inform specific implementation strategies.

\subsection{Conclusions}

The six chapters which follow show that around the world, in diverse education systems, governments are advancing policies to support teacher professional development at scale. The cases included in this study reflect two basic approaches: those that provide professional development opportunities to the majority of teachers in the system, and those that work with a defined target population of teachers. These approaches reflect partially the principles supported by the research-based evidence reviewed in this chapter as particularly effective. In this section I examine how these six cases compare with the conclusions of our previous study of teacher professional development (Reimers and Chung 2018a), and with some of the principles of effective teacher professional development practice summarized in this chapter.

Most of these programs reflect a conception of adult learning that sees it as socially situated and responding to current needs of teachers for learning. The three national programs recognize the socially situated nature of professional development in providing opportunity for local adaptation and for job embedded training in what is otherwise a fairly focused program of development. In contrast, the programs focusing on smaller networks of schools not only focus on broader needs for teachers but also reflect a view that sees teachers' learning as socially situated.

The mastery math program in England is designed to involve professional communities of teachers in schools, led by the lead specialists, recognizing the importance of job-embedded professional development and of collaborative practice. The program reflects a combination of top-down with bottom-up approach in that the focus on math instruction comes from top mandates, but there is ample autonomy for teachers to adapt the mastery learning approach in their schools in ways that best fit the needs of their teachers.

The program of professional development in rural schools in Colombia implements a coaching model in schools, providing even greater autonomy for communities in schools to focus on learning goals defined locally. There is indeed a clear recognition of the importance of offering professional development in schools.

The education reform in Mexico contemplated the need to create opportunities for professional development and collaboration at the school level, depending on existing structures and personnel. In that sense it, recognized the primacy of responding to the current needs of teachers.

The programs of residential schools in Telangana and the New Generation Schools in Cambodia create multiple forms of professional development at the school level, focusing on a wider range of competencies for teachers. 
The program in Burlington public schools is the one that most clearly focuses on transforming school culture, aligned with the idea of building schools as learning organizations. This program too reflects a view of teachers learning as socially situated, perhaps more so than any of the other programs.

All programs in this study involve sustained and extensive opportunities for teachers to build capacities, often extending an entire school year, and often spanning across multiple school years. All of them reflect the contemporary conception of teacher professional development that sees it as a long-term process as identified by Villegas-Reimers (2003) and not as the traditional staff development or in-service training. All of these programs reflect also the principles identified by Desimone (2009) as typical of high-quality professional development: content focus on subject matter, collective participation of teachers from the same school, active learning for teachers, long duration and coherence with the goals of the education policies that support them.

The intensity and frequency of these multiple opportunities for professional development is greater for the programs of smaller scale in Telangana, Cambodia and Burlington. The large scale of programs in England and Colombia provide more limited opportunities to teachers and have a narrower focus. The mastery approach was very systematic and apparently effective for the lead specialists, but not so much for the other teachers. This may illustrate the limitations of the cascade approach, and the limits of a program that allows for local adaptation which makes the program vulnerable to uneven support of local education authorities, to different interpretations of what mastery learning is, and to different choices at the school level regarding the use of textbooks. The program which was part of the education reform in Mexico was advanced too late in the term of the administration to effectively take hold; had it been implemented, the intention was to provide such opportunities.

Are the modalities of professional development varied? Do they include independent study of new material, discussion with peers and others, individual or group coaching, demonstrations of new practices, independent research projects and opportunities for reflection? This is less clearly the case for the three national programs in England, Colombia and Mexico than it is for the more focused programs in Telangana, Cambodia and Burlington. Perhaps this reflects a tradeoff between scale and complexity of the program. Institutional capacity of education ministries is limited, and it is arguably easier to scale relatively focused and simple initiatives than it is to scale the multitude of changes and supports necessary to help a school become a learning organization. It is noteworthy that in Burlington, where this approach is most visible, the effort involves only six schools. Telangana and Cambodia reflect mid-range efforts which offer a rich suite of opportunities for professional development in schools. Mexico's education reform seems to have contemplated doing this, but was constrained by the limited timeframe the administration had to implement the reforms.

England and Colombia depended on more limited and focused approaches of teacher professional development, in fact Colombia's program shifted from a program with a broader set of interventions at inception, to a simplified version focused exclusively on coaching and instructional materials on a narrow set of subjects, 
apparently with good results. Perhaps the first choice in developing an implementation strategy of an ambitious professional development agenda requires clear focus as to what will be the first steps. One option is to focus them on a small number of schools, as done in Telangana, Cambodia and Burlington, in which case it is possible to try a more complex theory of change. This approach assumes that the reform cycle will be long enough to allow learning from the small-scale effort to then feed that learning into a scaled-up version of the program. Alternatively, if a reform is going to be scaled from the outset, less may be more, and a clear focus as that illustrated by the examples of Colombia and England may be warranted. Mexico seems to have attempted to do too much in too little time, with no clear implementation strategy-or time to execute it - to produce visible results and with it the crucial support to stay the course. Mexico attempted to radically transform its education system, but was unable to secure initial buy-in from all relevant stakeholders. This compromised the ability to secure crucial support to stay the course, especially under the time pressure of a limited presidential term.

It is noticeable that none of the reforms examined in this book seems to be based on a theory of how education systems change. Beeby's powerful insights that educational change proceeded as countries moved through stages of educational development, reflecting largely the characteristics of their teachers, are still relevant. Not necessarily in that the stages he proposed may still be the most helpful, or in the idea that change needs to proceed sequentially from one stage through the next, or that no stage can be skipped, the idea that holds currency is the idea that one needs a clear model of how a system changes in order to have a strategy. An education system, or a school network, comprises a large number of individuals, with varying capacities. A strategy for educational change makes demands on the capacities of those individuals. A professional development strategy is a plan for how to close the gap between the capacities necessary to achieve the education strategy-as reflected in the curriculum goals, or in the new model of education - and the current capacities of those who work in the system. A clear model for how to close that gap is necessary, and it needs to be more specific than to propose that staff should be trained in accordance with the new curriculum goals. Who should learn what? With what modalities? In what timeframe? With what resources? Answering these questions requires a model of how systems change. Beeby's contribution was precisely that it illustrated the power of having a model. I have elsewhere offered a multidimensional model of how educational systems change that emphasizes the importance of attending to the cultural, psychological, professional, institutional and political dimensions of the process (Reimers 2020b). As evidenced by the chapters in this book, the absence of such models is a serious gap in the development of the implementation strategies of these reforms.

Does the curriculum of the programs examined cover a blend of capacities, from a broad focus on helping students develop specific capacities to a highly granular identification of particular pedagogies and instructional practices that can help students gain those skills? This is only visible in the three programs taking place in more focused networks of schools in Telangana, Cambodia and Burlington, but not in the national programs in England, Colombia and Mexico. 
Does the curriculum of these various programs reflect a view of learning which includes cognitive skills, in interaction with dispositions and socio-emotional skills? All the programs examined reflect an expansion in the ambition of curriculum goals, but not necessarily a broad conception of goals, including cognitive and socioemotional skills. For the national programs in England and Colombia, the focus is decidedly on cognitive skills. The program in Mexico had an ambitious set of curriculum goals, but it was not immediately implemented, largely because of political discontinuities, but perhaps also because of the complexity of developing a largescale implementation strategy and an effective communication strategy to implement it. The programs in Telangana and Burlington reflect a focus on a range of cognitive and socio-emotional skills, and the program in Cambodia reflects a broader and deeper set of cognitive goals.

Do these programs of professional development include exposure to visible routines, protocols and instructional practices, where teachers see in practice new forms of instruction or assessment? This is most clearly the case in the Math Mastery program in England and in Todos a Aprender in Colombia where textbooks offered clear structure and focus to the professional development, and in the professional development offered in some subjects in the Telangana residential schools program. In addition, lesson planning and follow-up and specific feedback were important features of the programs in Colombia and England. In Mexico, with a long-standing tradition of national textbooks and instructional resources, several publications were produced to guide teachers in understanding the goals of the new curriculum and to suggest activities to implement it, but these were not integrated into effective programs of professional development that reached a significant number of teachers by the time the end of the period of the administration interrupted the reform. The programs in Burlington used various resources, particularly evaluative resources, to support teachers in developing specific goals for instruction and for their own development. Similar to Burlington, teachers in Cambodia are engaged in structured career path planning, setting and monitoring their own professional development goals with the support of a mentor.

Do these programs rely on a mix of opportunities for learning situated in the context of the schools where teachers work? This is particularly the case in the three programs focused on networks of schools, most clearly in Burlington Public schools, and also in Telangana and Cambodia. There is a narrower focus in the cases of England and Colombia. The Mexico program only implemented a few professional development activities and they too had a narrower focus.

Is it the case that to support the intensive and sustained activities of professional development that these various programs advance, the organizations in charge build a range of partnerships with institutions outside of schools that contribute various types of resources? The national programs in England, Colombia and Mexico have a decided government and top-down emphasis, with limited opportunity for building institutional partnerships among schools and other organizations. In Colombia's case, however, the inception of the program benefited from the leadership of an advocacy organization in civic society. Telangana and Burlington do illustrate the development 
of such partnerships to enhance the capacity of the school, as did the New Generation Schools program in Cambodia.

All these programs see teacher practice as situated in specific organizations and social contexts, and in general adopt a whole-school approach, rather than helping individual teachers increase their capacity. All these programs develop capacities among teachers to advance pedagogies with the goal of developing competencies that are not formally assessed in the school or school system, although several of them also use the results of regular assessments to support professional development.

To some extent all the organizations that support these various programs model a learning orientation. Because these are all government-led programs, the units that lead these programs demonstrate the capacity to use feedback loops to monitor implementation and course correct when necessary. This is less clear in the case of national programs in England and Mexico, but evident in Colombia's national program which was reformulated as a result of evidence that it was not achieving the intended impact. The smaller scale programs all demonstrate the capacity to adapt and course correct as a result of learning from implementation.

There are several additional lessons emerging from these studies which go beyond the conclusions of our earlier study of teacher professional development. Several of these efforts, especially the national reforms in England, Colombia and Mexico, used the results of cross-national assessments, highlighting the low levels of student achievement and the disparities in achievement, to open space for reform.

Clearly politics plays an important role in a national effort of professional development. While all these programs benefited from strong support from the national government - or from the district in the case of Burlington and from the State in the case of Telangana-such support was also a double-edged sword in the case of Mexico. The ambitious education reform was so clearly a priority of the administration, and so visibly identified with it, that a change in government caused the reform to be discontinued. In contrast, in Colombia, Todos a Aprender, while it received strong support from the Minister, the reform was not visibly identified as one of the flagship programs of the administration-in the way in which another program, a scholarship program to promote college access was - in this way the reform continued after a change of President in Colombia-but the more visible college access program did not. There are additional reasons the design of the reform in Colombia received more political support than Mexico's reform. In Colombia's case there was extensive dialogue among teachers and with teacher unions about the program. Such dialogue was impossible in Mexico's case given that a crucial component of the reform was to eliminate the control that the teacher union exercised over teacher appointments and promotions. Most of these programs garnered sufficient political support to stay the course, with the exception of Mexico's. Civil society played a key role in providing such support and in ensuring the continuity of these efforts in Cambodia and Colombia.

While these chapters do not tell us which programs "worked" in terms of achieving their intended results or in terms of being able to stay the course for a sufficiently long period to transform the culture of schools and transform them into "learning organizations", they show that it is indeed possible to design programs that aim at 
professionalizing teaching at scale. Such design can be informed not only by known principles about what has been shown to be effective, mostly in studies of programs of a smaller scale, but also by what is known about how to design an operational strategy that governments can implement. There are obvious opportunities to combine what these various programs did in designing new programs. Mexico's strategy, for example, given the ambitious goals of the reform, would have benefited from a strategy of teacher professional development at the level of specificity of the strategies illustrated in the programs in Telangana, Cambodia or Burlington. If Colombia's and England's strategies are the first step in a long-term process that hopes to eventually make schools and learning organizations embrace the ambitious curriculum goals that Mexico's reform embraced, they need to show how they will evolve to produce conditions along the lines of those contemplated in Burlington, Cambodia and Telangana. Those three in turn, if they are the first step of more ambitious plans to scale these reforms to greater numbers of schools, teachers and students, will need a strategy that shows how what is achieved in a small number of schools will be used to support change in greater numbers of schools. We hope the analysis of these six programs will contribute to more effective design of such implementation strategies of large-scale education reform in the future so that all students can develop the skills they need to find purpose for themselves and to contribute to building a better world.

\section{References}

Avalos, B. (2011). Teacher professional development in teaching and teacher education over ten years. Teaching and Teacher Education, 27, 10-20.

Barber, M., Moffit, A., \& Kihn, P. (2011). Deliverology 101: A field guide for educational leaders. Thousand Oaks, CA: Corwin Press.

Barrera-Pedemonte, F. (2016). High-Quality teacher professional development and classroom teaching practices: Evidence from Talis 2013. OECD Education Working Papers No 141. Paris: OECD.

Beeby, C. (1966). The quality of education in developing countries. Cambridge, MA: Harvard University Press.

Beeby, C. (1992). The biography of an idea. Wellington, New Zealand: New Zealand Council for Educational Research.

Borko, H. (2004). Professional development and teacher learning: Mapping the terrain. Educational Researcher, 33(8), 3-15.

Darling-Hammond, L., Hyler, M., \& Gardner, M. (2017). Effective teacher professional development. Palo Alto, CA: Learning Policy Institute.

Delors, J., et al. (1996). Learning, the treasure within. Report to UNESCO of the international commission for education in the 21 st century. Paris: UNESCO Publishing.

Desimone, L. (2009). Improving impact studies of teachers' professional development: Toward better conceptualizations and measures. Educational Researcher, 38(3), 181-199.

Faure, E., Herrera, F., Kaddoura, A. R., Lopes, H., Petrovsky, A., Rahnema, M., \& Ward, F. (1972). Learning to be: The world of education today and tomorrow. Paris: UNESCO.

Fullan, M. (1987). Implementing the implementation plan. In M. Widen \& I. Andrews (Eds.), Staff development for school improvement. New York: Falmer Press.

Guskey, T. (2002). Professional development and teacher change. Teachers and Teaching, 8(3), 381-391. 
Hattie, J. A.C. (2009). Visible learning: A synthesis of over 800 meta-analyses relating to achievement. New York, NY: Routledge.

Ingvarson, L., Meiers, M., \& Beavis, A. (2005). Factors affecting the impact of professional development programs on teachers' knowledge, practice, student outcomes and efficacy. Education Policy Analysis Archives, 13(10), 1-26.

Jensen, B., Hunter, A., Sonnemann, J., \& Burns, T. (2012). Catching up: Learning from the best school systems in East Asia. Grattan Institute.

Jones, S., \& Doolittle, E. (2017). Social and emotional learning: Introducing the issue. The Future of Children, 27(1), 3-12.

Kools, M., \& Stoll, L. (2017). What makes a school a learning organization? OECD Education Working Papers, No. 137. Paris: OECD Publishing.

Kraft, M., Blazar, D., \& Hogan, D. (2018). The effect of teacher coaching on instruction and achievement: A meta-analysis of the causal evidence. Review of Educational Research, 88(4), $547-588$.

Liang, X., Kidwai, H., \& Zhang, M. (2016). How Shanghai does it. Insights and lessons from the highest-ranking education system in the world. Washington, DC: World Bank Group.

Mehta, J., \& Fine, S. (2019). In search of deeper learning: The quest to remake the american high school. Cambridge, MA: Harvard University Press.

OECD. (2019). TALIS 2018 results (Volume I): Teachers and school leaders as lifelong learners. Paris: OECD Publishing.

Pellegrino, J. W., \& Hilton, M. L. (Eds.). (2012). Education for life and work: Developing transferable knowledge and skills in the 21st century. Washington, DC: The National Academic Press.

Reimers, F. (Ed.). (2017). Empowering all students at scale. Charleston, SC: CreateSpace.

Reimers, F. (Ed.). (2019). Letters to a new minister of education. Seattle, WA: KDP.

Reimers, F. (Ed.). (2020a). Audacious education purposes. How governments transform the goals of education systems. Springer. In press.

Reimers, F. (2020b). Educating students to improve the world. Springer. In press.

Reimers, F., Bullrich, E., Cardozo, B., Edwards, D., Giannini, S., Goyal, V., ... Wigdortz, B. (2017a). Connecting the dots to build the future teaching and learning. London: Varkey Education Foundation.

Reimers, F., et al. (2017b). Empowering students to improve the world in sixty lessons. Charleston, SC: CreateSpace.

Reimers, F., Chopra, V., Chung, C., Higdon, J., \& O’Donnell, E. (2016). Empowering global citizens. Charleston, SC: CreateSpace.

Reimers, F., \& Chung, C. (Eds.). (2016). Teaching and learning for the twenty first century. Cambridge, MA: Harvard Education Press.

Reimers, F., \& O’Donnell, E. (Eds.). (2016). Fifteen letters on Singapore. Morrisville, NC: Lulu Publishing.

Reimers, F., \& Chung, C. (Eds.). (2018a). Preparing teachers to educate whole students: An international comparative study. Cambridge, MA: Harvard Education Publishing.

Reimers, F., Ortega, M. E., \& Dyer, P. (2018b). Learning to improve the world. How Injaz Al-Arab helps youth in the Middle East develop and entrepreneurial mindset. Charleston, SC: CreateSpace.

Reimers, F., et al. (2018c). Learning to collaborate to advance the global common good. Charleston, SC: CreateSpace.

Röhrs, H. (1994). Maria Montessori (1870-1952). PROSPECTS: The Quarterly Review of Comparative Education, XXIV (1/2) (89/90), 169-183. (Paris, UNESCO: International Bureau of Education)

Schleicher, A. (2018). World class. How to build a 21st century school system. Paris: OECD.

Soëtard, M. (1994a). Johann Heinrich Pestalozzi (1746-1827). Prospects: The Quarterly Review of Comparative Education, XXIV(1/2), 297-310 (Paris, UNESCO: International Bureau of Education). 
Soëtard, M. (1994b). Jean-Jacques Rousseau (1712-78). PROSPECTS: Quarterly Review of Comparative Education, XXIV(3/4), 423-438 (Paris, UNESCO: International Bureau of Education).

Villegas-Reimers, E. (2003). Teacher professional development: An international review of the literature (Quality education for all). Paris: International Institute for Educational Planning. Retrieved January 15, 2018, from https://www.teachersity.org/files/PDF/UNESCO\%20$\% 20$ Teacher\%20Professional\%20Development.pdf.

Villegas-Reimers, E., \& Reimers, F. (1996, September). Where are 60 million teachers? The missing voice in educational reforms around the world. Prospects, 25(3), 469-492.

Weiss, C. (1998). Evaluation. Methods for studying programs and policies. New Jersey: Prentice Hall.

Westbrook, R. (1993). John Dewey 1859-1952. Prospects: The Quarterly Review of Comparative Education, XXIII(1/2), 277-291 (Paris, UNESCO: International Bureau of Education).

World Bank. (2018). World development report 2018: Learning to realize education's promise. Washington, DC: World Bank.

Open Access This chapter is licensed under the terms of the Creative Commons Attribution 4.0 International License (http://creativecommons.org/licenses/by/4.0/), which permits use, sharing, adaptation, distribution and reproduction in any medium or format, as long as you give appropriate credit to the original author(s) and the source, provide a link to the Creative Commons license and indicate if changes were made.

The images or other third party material in this chapter are included in the chapter's Creative Commons license, unless indicated otherwise in a credit line to the material. If material is not included in the chapter's Creative Commons license and your intended use is not permitted by statutory regulation or exceeds the permitted use, you will need to obtain permission directly from the copyright holder. 